\title{
What is the role of video laryngoscopy in pre- hospital care?
}

\author{
Wolfgang G Voelckel ${ }^{1,2}$ \\ From London Trauma Conference 2013 \\ London, UK. 10-13 December 2013
}

\begin{abstract}
Background
Direct laryngoscopy is the primary method for performing tracheal intubation in the pre-hospital setting. Failure to quickly establish an airway can result in hypoxemia, aspiration, neurologic damage, cardiovascular complications, and death. In-hospital data derived form 50,760 apparently normal patients undergoing surgery suggest that difficult laryngoscopy occurs in 5.8\% [1]. When intubation is required in a pre-hospital scenario, the incidence of difficult laryngoscopy is doubled even when experienced anaesthesiologists are involved, and expected to reach some $20 \%$ when less qualified operators are in charge [2]. Thus, failed intubation rates in the emergency medical service may be as high as $7 \%$ [3].
\end{abstract}

\section{Technique}

Videolaryngoscopy is a relatively new technology developed to improve the success rate of tracheal intubation. A high-resolution micro camera mounted on the tip of a curved blade connected to small portable digital monitor improves the view of the vocal cords and subsequently the success rate of direct laryngoscopy. During direct laryngoscopy, the operator visualizes the larynx from outside the oral orifice. The distance between the vocal cords and the laryngoscopist's eye is significant $(30-40 \mathrm{~cm})$. This reduces the angle of view to some $15^{\circ}$ with a classic laryngoscope. Suboptimal alignment of the oral-, pharyngeal- and laryngeal-axis, as well as multiple anatomic orpathologic factors can make direct visualization of the airway difficult or even impossible. Videolaryngoscopy significantly widens the angle of view since the digital camera and light source are inserted very close $(2-3 \mathrm{~cm})$ to the larynx.

Videolaryngoscopes or alternative optic devices providing a "view around the corner" may be categorized

Department of Anaesthesiology and Critical Care Medicine, AUVA Trauma Centre Salzburg, Austria

Full list of author information is available at the end of the article according to design, handling and guidance of the tracheal tube.

\section{General considerations}

There is sufficient scientific evidence that videolaryngoscopy improves the visualization of the vocal cord when established scoring systems such as the Cormack and Lehane scale are employed. It is noteworthy that despite an improvement in view, the operator may still be unable to pass a tracheal tube through the glottis. Thus, the key to a successful outcome is not solely due the view obtained but related to the ease of inserting the tracheal tube. This must be considered in future studies evaluating the role of videolaryngoscopy in the pre-hospital setting. In this regard, a three part scoring system comprising the device employed, the view (full, partial, none) and the ease of intubation (easy, modified, unachievable) has been suggested [4]. In addition, performance of videolaryngoscopy in patients endangered by mucus, blood or vomitus in the upper airway must be addressed. Finally, videolaryngoscopy will be challenged by typical pre-hospital environmental obstacles, i.e. bright ambient light, humidity, rain, snowfall, extreme cold or heat. In this regard, a robust and reliable device is key when used outside the hospital.

\section{Learning curve}

Similar to the learning curve for direct laryngoscopy, new airway devices require significant training and experience. Manikin studies do not allow a comprehensive appreciation of the training needed. At present, available studies suggest a fairly low number of intubations needed to obtain the required skills [5].

\section{Scientific evidence}

Studies and case reports suggest that intubation success rates may be as high as $99 \%$ when direct laryngoscopy was impossible [6]. However, in a systematic review addressing 

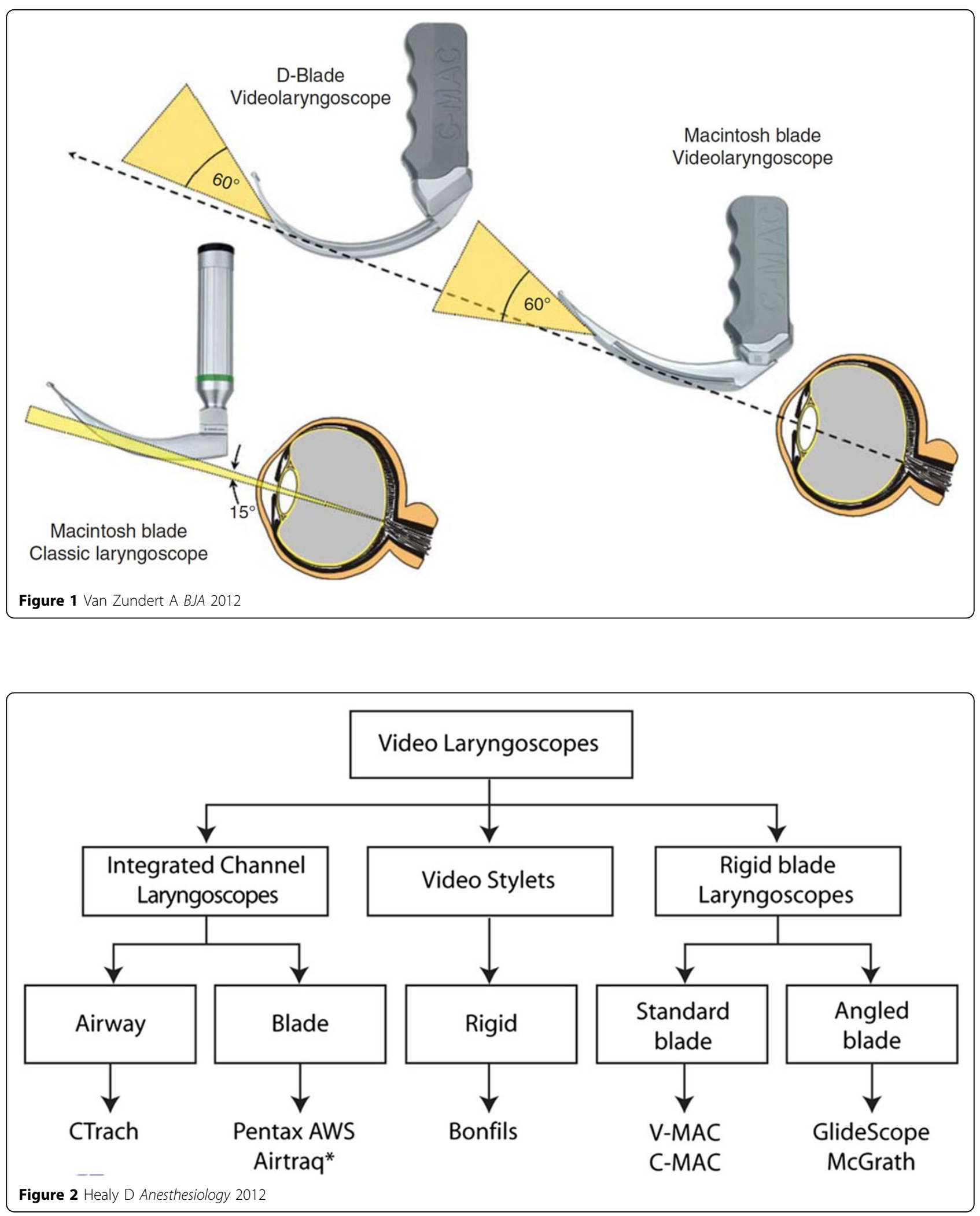
Table 1

\begin{tabular}{|c|c|c|c|}
\hline & Good evidence (Level 1+) & Weak evidence (Level 3) & No evidence \\
\hline \multirow[t]{5}{*}{ Subjects at higher risk of difficulty during $\mathrm{DL}$} & Airtraq & Bonfils & McGrath \\
\hline & CTrach & Bullard & \\
\hline & GlideScope & & \\
\hline & Pentax AWS & & \\
\hline & V-MAC & & \\
\hline \multirow[t]{6}{*}{ Known difficult DL } & & Airtraq & McGrath \\
\hline & & Bonfils & V-MAC \\
\hline & & Bullard & \\
\hline & & CTrach & \\
\hline & & GlideScope & \\
\hline & & Pentax AWS & \\
\hline \multirow[t]{6}{*}{ Failed DL } & & Airtraq & Bullard \\
\hline & & Bonfils & V-MAC \\
\hline & & CTrach & \\
\hline & & GlideScope & \\
\hline & & McGrath & \\
\hline & & Pentax AWS & \\
\hline
\end{tabular}

the potential role of videolaryngoscopy in successful orotracheal intubation [7], the evidence found for efficacy in difficult airway management was limited (Table 1).

\section{Evidence obtained in pre-hospital studies}

The number of randomized control trials (RCT) addressing videolaryngoscopy in the pre-hospital setting is still low. Presently, there is only one RCT comparing direct laryngoscopy (DL) with the AirTraq in 212 patients. Success rates for DL were found to be $98 \%$ whereas the AIrTraq intubation success was as low as $47.2 \%$ [8]. The authors concluded that besides some technical shortcomings, pre-study training was insufficient, although operators felt confident using the device. Preliminary reports and prospective observational studies addressing the C-Mac videolaryngoscope in helicopter $[9,10]$ and ground emergency medical services [11] found the device suitable and useful for prehospital emergency tracheal intubations with complicated airway conditions.

\section{Conclusion}

Presently, the data available does not or insufficiently address the specific aspects of intubation in the exposed pre-hospital environment. In addition, some typical problems such as on-going bleeding or vomitus in the upper airway have still not been evaluated in pre-hospital RCTs. Since the C-Mac videolaryngoscope (K. Storz, Tuttlingen Germany) combines a conventional designed laryngoscope with video imaging, this concepts merits appreciation and may already be implemented in field care.

In conclusion, videolaryngoscopy is a rapidly growing technology. In the future, video laryngoscopy will dominate the field of emergency airway management.

\section{Competing interests}

The author declares no conflict of interest with the devices or the technology addressed in this summary.

\section{Authors' details}

${ }^{1}$ Department of Anaesthesiology and Critical Care Medicine, AUVA Trauma Centre Salzburg, Austria. ${ }^{2}$ ÖAMTC Air Rescue, Vienna, Austria.

\section{Published: 7 July 2014}

\section{References}

1. Shiga T, Wajima Z, Inoue T, Sakamoto A: Predicting difficult intubation in apparently normal patients: a metaanalysis of bedside screening test performance. Anesthesiology 2005, 103(2):429-37.

2. Breckwoldt J: Expertise in prehospital endotracheal intubation by emergency medicine physicians-Comparing 'proficient performers' and 'experts'. Resuscitation 2012, 83(4):434-9.

3. Timmermann A, Russo SG, Eich C, Roessler M, Braun U, Rosenblatt WH, Quintel M: The out of hospital esophageal and endobronchial intubations performed by emergency physicians. Anesth Analg 2007 104(3):619-23.

4. Swann AD, English JD, O'Loughlin EJ: The development and preliminary evaluation of a proposed new scoring system for videolaryngoscopy. Anaesth Intensive Care 2012, 40(4):697-701.

5. DiMarco P, Scattoni L, Spinoglio A, Luzi M, Canneti A, Pietropaoli P, Reale C: Learning curves of the Airtraq and the Macintosh laryngoscopes for tracheal intubation by novice laryngoscopists: a clinical study. Anaesth Analg 2011, 112(1):122-125.

6. Asai T, Liu EH, Matsumoto S, Hirabayashi Y, Seo N, Suzuki A, Toi T, Yasumoto K: Use of the Pentax-AWS in 293 patients with difficult airways. Anesthesiology 2009, 110(4):898-904

7. Healy D: A systematic review of the role of videolaryngoscopy in successful orotracheal intubation. Anesthesiology 2012, 12:32.

8. Trimmel H, Kreutziger J, Fertsak G, Fitzka R, Dittrich M, Voelckel : Use of the Airtraq laryngoscope for emergency intubation in the prehospital setting: a randomised controlled trial. Crit Care Med 2011, 39(3):489-93.

9. Carlson J: Variables associated with successful intubation attempts using video laryngoscopy: a preliminary report in a helicopter emergency medical service. Prehosp Emerg Care 2012, 16(2):293-8.

10. Hossfeld B, Frey K, Lampl L, Doerges V, Helm M: Improving glottic visualization in EMS: comparing direct laryngoscopy and C_MAC PM videolaryngoscopy. Poster presentation 2012. 
11. Cavus E: The C-MAC videolaryngoscope for prehospital emergency intubation: a prospective, multicentre, observational study. Emerg Med $J$ 2011, 28(8):650-3.

\section{doi:10.1186/1757-7241-22-S1-A6}

Cite this article as: Voelckel: What is the role of video laryngoscopy in pre-hospital care? Scandinavian Journal of Trauma, Resuscitation and Emergency Medicine 2014 22(Suppl 1):A6.

Submit your next manuscript to BioMed Central and take full advantage of:

- Convenient online submission

- Thorough peer review

- No space constraints or color figure charges

- Immediate publication on acceptance

- Inclusion in PubMed, CAS, Scopus and Google Scholar

- Research which is freely available for redistribution

Submit your manuscript at www.biomedcentral.com/submit
() Biomed Central 